\title{
Species diversity and nestedness of ant assemblages in an urban environment
}

\author{
PIOTR ŚLIPIŃSKI, Micha£ ŻMIHORSKI and WOJCIECH CZECHOWSKI \\ Museum and Institute of Zoology, Polish Academy of Science (PAS), Wilcza 64, 00-679 Warsaw, Poland; \\ e-mail: piotrs@miiz.waw.pl
}

Key words. Formicidae, biodiversity conservation, city, nestedness, redundancy analysis, urban pressure

\begin{abstract}
Ant assemblages were studied in Warsaw in the context of the effects of urban pressure. Four types of urban greenery were selected: (1) green areas bordering streets, (2) in housing estates, and (3) in parks, and (4) patches of urban woodland. In total, there were 27 species of ants. In terms of the total ant activity density, Lasius niger predominated in all the the lawn biotopes (1-3) and Myrmica rubra in the wooded areas. Ant species diversity was highest in parks and wooded areas and lowest in green areas bordering streets. In contrast, activity density was highest in green areas bordering streets and lowest in wooded areas. Some species are found only in a few habitats. Stenamma debile, Lasius brunneus, L. fuliginosus and Temnothorax crassispinus almost exclusively occurred in wooded areas, whereas L. niger was most often found in lawn biotopes. Myrmica rugulosa and Tetramorium caespitum were most abundant in green areas bordering streets, while in parks Lasius flavus, Formica cunicularia and Solenopsis fugax were most abundant. In general, the ant assemblages recorded showed a significantly nested pattern, with biotope type being a significant determinant of nestedness. The assemblages found in green areas in housing estates and bordering streets constituted a subsample of the assemblages in parks and wooded areas. Ant species were non-randomly distributed in this urbanized landscape and the species recorded in the most transformed biotopes constitute subsamples of those inhabiting less transformed biotopes. This finding emphasizes the importance of wooded areas for the maintenance of biodiversity in urban areas.
\end{abstract}

\section{INTRODUCTION}

Urbanization is a global and unavoidable process affecting an increasing amount of rural landscape each year (e.g. Botkin \& Beveridge, 1997; Clarke et al., 2008). However each process, including the rapid development of urbanized areas, has consequences. Biotic impoverishment seems unavoidable if one considers the severe pressures inflicted on urban environments: changes in the vegetation brought about by its management or that resulting from general human activity (Rosenberg et al., 2000; Mabelis 2005), warming of local microclimates (e.g. Angilletta et al., 2007), fragmentation of the habitats of plant and animal species (e.g. Clarke et al., 2008; Yasuda \& Koike, 2009), significant levels of pollution and very often increased soil salinity (Jim, 1998). All these factors unavoidably affect assemblages of urbandwelling animals. On the other hand urbanization and man-made habitat transformation is uneven in the landscape and some areas in a city, e.g. parks, woodlots etc. contain relatively well preserved vegetation. The mosaic of transformed land and well preserved patches provides an opportunity to observe the response of particular components of biodiversity to various levels of transformation at relatively small spatial scales.

One of the most important and functionally crucial group of invertebrates that can be used to assess the biological consequences of urbanization are ants (e.g. Folgarait, 1998; Penev et al., 2008; Pećarević et al., 2010), a group of insects that are generally known to be indicators of changes in the environment (e.g. Agosti et al., 2000; Kaspari et al., 2000; Andersen et al., 2002; Beever et al., 2003; Yamaguchi, 2004; Philpott et al., 2010). There are studies on the effect of the pressure of urbanization on ant biodiversity in several cities but most of these studies just present lists of species (Gaspar \& Thirion, 1978; Dauber \& Eisenbeis, 1997; Lapeva-Gjonova \& Atanasova, 2004; Antonova, 2005). Increasing numbers of publications on the effect of urbanization on ant assemblages (Folgarait, 1998; Yamaguchi, 2004; Antonova \& Penev, 2006; Penev et al., 2008; Vepsäläinen et al., 2008; Pećarević et al., 2010) indicate that the abundance of ants in urbanized landscapes can provide important information on other taxa and the whole ecosystem.

In this paper we address the spatial variability of ant assemblages in an urbanized landscape using data collected in the 1970s in Warsaw. The data originated from an extensive survey of the species composition of the fauna in four urban biotopes in Warsaw (Pisarski, 1982; Pisarski \& Czechowski, 1978; Vepsäläinen \& Pisarski, 1982; Pisarski \& Vepsäläinen, 1987; Czechowski et al., 1990; Czechowski \& Pisarski, 1990; Czechowski, 1991; Czechowska \& Czechowski, 2003; Czechowski \& Ślipiński, 2008) for which the main determinants of spatiotemporal patterns in species composition and abundance were unknown. These biotopes differ greatly from each other in terms of the type and intensity of human pressure and degree of habitat transformation, and provide an opportunity to study the diversity of ant assemblages along a gradient of urbanization. More specifically, we (1) investigate the structure of ant assemblages recorded in the main types of urban green areas in Warsaw. For this purpose we use the nested concept that assumes a non-random distribution of species in the samples from different places, which in this particular survey are the 
different biotopes studied. We attempted to test if ant assemblages in the more transformed biotopes are a subsample of those in less degraded and more natural biotopes. Bearing in mind that the transformation of habitats by man is an important determinant of the nested pattern in urban birds (Fernandez-Juricic, 2000, 2002) we hypothesized that ant assemblages are nested and those in simplified biotopes are subsets of those in more diverse biotopes. More specifically, we expect that ant assemblages occurring in natural biotopes will include assemblages that occur in transformed biotopes plus some additional species that do not occur in these impoverished biotopes. Verification of this hypothesis would indicate the importance of less transformed biotopes in maintaining biodiversity and the role they have as refugia in addition to their recreational value (see e.g. Kadlec et al., 2008). Moreover we (2) describe the variability in species richness of ants and their diversity along a gradient of urbanization, (3) assess the response of species to increasing urban pressure in particular biotopes and (4) present the species composition and ecological profile of an urban myrmecofauna.

\section{MATERIAL AND METHODS}

\section{Urban green areas in Warsaw}

Urban Warsaw $\left(52^{\circ} 20^{\prime} \mathrm{N}, 21^{\circ} 00^{\prime} \mathrm{E}\right.$, ca. $40 \mathrm{~m}$ a.s.l.) covers ca. $500 \mathrm{~km}^{2}$. The natural vegetation for this area is lime-oakhornbeam (Tilio-Carpinetum) woodland. Urbanization has almost completely destroyed the primeval woodlands, with only a few parches of forest remaining within the city, mainly in the suburbs, plus a few highly modified patches in built-up areas. Grassland, i.e. more or less open lawns of anthropogenic origin, is the main substitute community. They constitute nearly $70 \%$ of Warsaw's green areas. The remaining green areas are various types of thickets, allotments and home gardens, etc. There are approximately 70 species of plants recorded growing in the lawns, with grasses predominating in terms of quantity. In terms of phytosociology, urban lawns resemble pasture communities (the Cynosurion alliance) or moist meadows (the Arrhenatherion alliance), both of which belong to the order Arrhenatheretalia (see Matuszkiewicz, 1981).

The four main biotopes (space with similar abiotic conditions; Krebs, 1994) in Warsaw are: (1) green areas bordering streets, (2) green areas in housing estates, (3) parks and (4) woodlands. The categories 1-3 are more or less open lawns.

(1) The poorest and most homogenous biotope, usually consist of 8-10 species of herbaceous plants, including 5-6 species of grasses. The impoverished vegetation growing in this biotope resembles a poor pasture. Roadside lawns often resemble xerophilic sandy grasslands of the class Sedo-Sclerantea, sometimes with the addition of mesohalophytes. Soils tend to be degraded, heavily polluted (including salinity) and dry.

(2) This a highly variable biotope in terms of the size and shape of individual plots, cultivation and intensity of horticultural use. Manicured lawns within modern, vast residential quarters resemble those in parks, whereas neglected green areas (e.g. in back-yards in high-density housing estates) or ruderal plant communities belong to the order Onopordetalia, which spontaneously form in newly developed areas (referring to the situation at the time of the study, i.e. the 1970s). The soils are relatively free of chemical pollutants and generally more fertile than elsewhere due to the large amount of organic matter (dog waste, pigeon feed) in these areas.
(3) Parks contain the floristically richest lawns, consisting of 20-25 species of herbaceous plants, including 7-10 species of grass. In addition, there are often single old trees or clusters of trees and numerous shrubs growing in parks. Park lawns are usually frequently mowed and the hay is removed. The soil is relatively free of pollutants, but mineral fertilizers and herbicides are periodically applied. Warsaw parks, while relatively homogenous in terms of how they are managed, vary greatly in size, from a few to about 90 ha. For more detailed descriptions of these three types of urban green areas see Kubicka et al. (1986). For the effect of management on the fauna of green urban areas of Warsaw see Mabelis (2005).

(4) Woodlands consist of the few patches of old tree that remain in Warsaw. Although some of them form parts of parks, they are distinguished as a separate biotope type because of their specific vegetative structure, origin and management, which are totally different from those of the artificially established and intensely cultivated urban lawns. These urban woods tend to differ in many respects from the original lime-oakhornbeam forest. They contain proportionately fewer oaks (Quercus spp.) and hornbeams (Carpinus betulus) and more maples (especially Acer negundo), robinias (Robinia pseudoacacia) and limes (Tilia spp.).

\section{Plots, sampling and material}

Altogether, 50 plots representative of the four types of Warsaw urban green areas were studied (14 in streets, 11 in housing estates, 14 in parks and 11 in wooded areas). Almost all of them were situated in that part of Warsaw that is on the leftbank of the Vistula (Fig. 1) and all are in potential TilioCarpinetum forest habitat. The plots were selected to reflect the different types of urban greenery and intensity of urban pressure. Ants were systematically collected in the years 1974-1978 using mainly pitfall traps (glass cylinders $4 \mathrm{~cm}$ in diameter, $10 \mathrm{~cm}$ deep and containing ethylene glycol). In individual study plots, depending on their size, 10-25 traps were placed in a row, $1 \mathrm{~m}$ apart each. Each trapping period lasted two weeks. During the first year (1974) trapping occurred throughout the season. In the following years, there was one period of trapping every month from April to October, i.e. seven annually. Every plot was studied for 1-5 seasons; in the majority of cases not less than 2-3 seasons (only a few plots, where traps were frequently destroyed, were studied for only one year). In total, ca. 15,000 traps were set and over 200,000 ants were collected and determined. The activity density index was used in the analyses. This index was the mean number of individuals caught by 10 traps over a period of 14 days. This index is used in many of the publications of the Institute of Zoology PAS on the epigean fauna (e.g. Kubicka et al., 1986; Pisarski, 1990).

\section{Statistical analysis}

We investigated the nestedness of ant assemblages in the green areas studied. The nestedness concept relates to the nonrandom distribution of species across samples and the hierarchical structure of the species found in the different plots (Atmar \& Patterson, 1993; Ulrich et al., 2009). This means that assemblages found in some plots (species-poor plots) constitute sub-samples of assemblages found in other (more species-rich) plots. If this is so, then species found in poor plots are also present in rich plots and therefore the species composition of poor plots is said to be nested within the species composition of rich plots. From an ecological perspective such a pattern is important as it indicates that all the species found in poor-species plots are also present in rich-species plots, but there are also unique species in the rich plots, which do not occur in poor-species plots. 


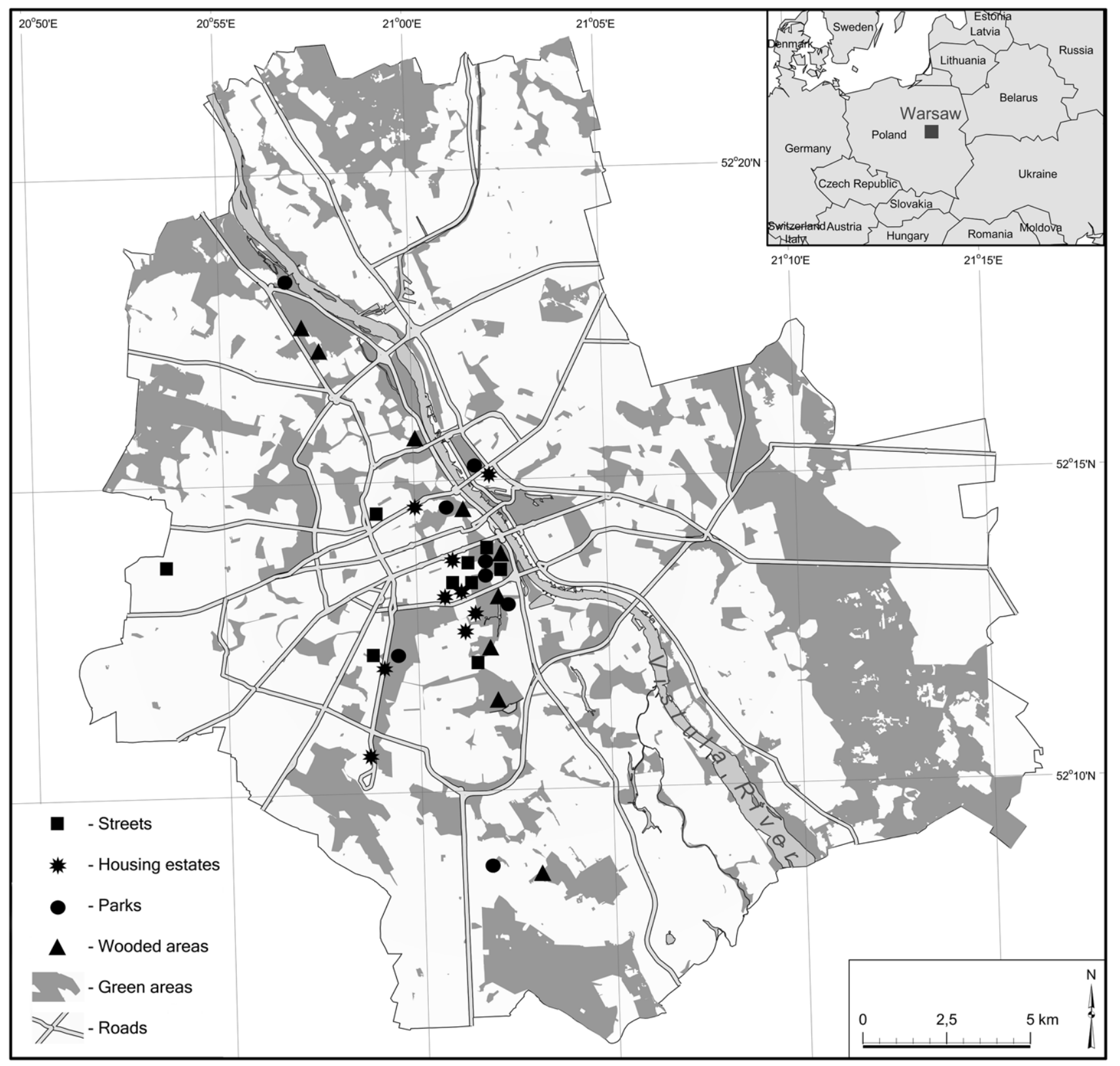

Fig. 1. Location of the sampling sites in four types of green area (biotopes) in Warsaw.

In this context the community in poor-species plots does not contribute to the overall species richness as all the species are present in rich-species plots. For this purpose we used the species per sample matrix as an input (all samples and species included) and the NESTEDNESS program (Ulrich et al., 2009) as the analytical software. We computed the nestedness of the matrix using the sequential swap as a null model for randomization with 500 permutations (Ulrich, 2006). The matrix temperature was used as a measure of the nestedness of the packed matrix and this temperature was compared to a simulated temperature (calculated for replicated random matrices) with $95 \%$ confidence intervals in order to confirm the significance of the nested pattern. The temperature used here estimates the level of nestedness of a given data set: cold matrices are significantly nested, whereas hot ones are not nested (e.g. random distribution) (Atmar \& Patterson, 1993). Finally, we tested whether the rank of samples in a packed matrix was randomly distributed across the green areas investigated. For this purpose, we ranked samples according to their order in a packed matrix $(1$ st rank $=$ the species-richest sample) and compared the mean rank of the samples from each habitat using the Kruskal-Wallis nonparametric ANOVA implemented in SPSS 16.0 software.

We used rarefaction curves to assess the diversity of ant assemblages, using the Mao Tau estimator in EstimateS 8.00 software (Colwell, 2005). This estimator presents the expected cumulative number of ant species for a given number of randomly chosen samples. The value of this estimator gives a measure of species diversity (Gotelli \& Colwell, 2001; Colwell, 2005). We computed the Mao Tau estimator for the pooled material of all samples, as well as for the different types of urban green areas (= biotopes), comparing four independent curves. Additionally, we used the abundance-based coverage estimator (ACE) as an approximation of the total species richness corrected for the species not recorded during the study (see Chao et al., 2006). The ACE uses information on the rarest species to estimate the number of unseen species in the pooled material (Chao et al., 2006). The diversity index of the ant assemblage for each plot was calculated according to Levin's 

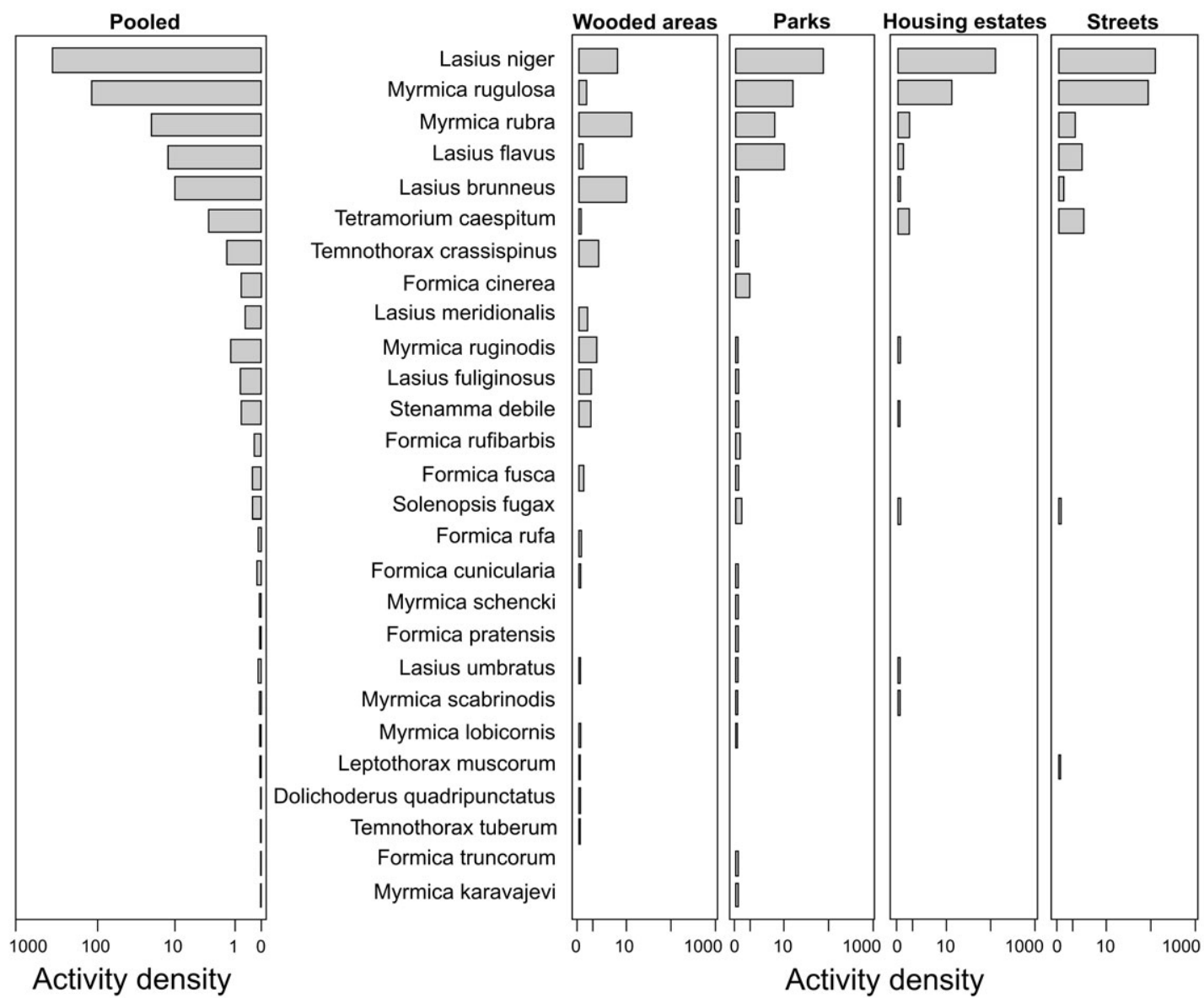

Fig. 2. Total activity density and that in each of the four biotopes of the different species of ants.

(1968) formula: $1 / \Sigma p_{i}^{2}$, where $p_{i}$ denotes the contribution of a given ant species to the overall assemblage in a given plot.

Then a redundancy analysis (RDA) implemented in CANOCO software (Lepš \& Šmilauer, 2003) was used to investigate the relationships between the distribution and activity density of ant species and habitat characteristics. We used activity density indices for all ant species in 50 plots as an input, and the four types of green areas and distance to the city centre as explanatory variables. The significance of the canonical axes of RDA was tested using the Monte Carlo test with 5000 permutations. Moreover, we used general additive models (GAM) implemented in CANOCO to visualize the variation in species richness and Shannon diversity along the two axes of the RDA. We used GAM with a Gaussian error distribution and identity link function.

\section{RESULTS}

Altogether, 27 ant species were recorded in all the plots in the Warsaw urban green areas studied (Fig. 2): eight species in green areas bordering streets, 11 in those in housing estates, 19 in wooded areas and 22 in parks (Fig. $2)$. From 4 to 13 species $(6.64 \pm 3.05$ on average $)$ occurred in particular plots in parks, 4 to $11(7 \pm 2.36)$ in wooded areas, 2 to $5(3.9 \pm 1.3)$ in the housing estates and 4 to $7(4.85 \pm 1.01)$ in green areas bordering streets.

\section{Nested pattern of the assemblages}

Ant assemblages in the city landscape were significantly nested. This means that the assemblages found in species-poor samples constituted subsets of species-rich samples, and the distribution of species across speciespoor and species-rich samples was not random. Therefore, the great majority of species found in species-poor samples can be found in species-rich samples. The matrix temperature was 10.29 and did not overlap the $95 \%$ confidence interval computed for 500 simulated matrices, which ranged from 10.94 to 14.58 (12.76 on average).

The sample rank in a packed matrix was not randomly distributed across the four biotopes studied: samples from wooded areas and parks had lower ranks (i.e. were species-richer) then samples from street and housing estate green areas (Fig. 3) (Kruskal-Wallis test, $\chi^{2}=$ $12.78, d f=3, P=0.005)$. This indicates that ant assemblages recorded in, for example, the housing estates constitute a non-random subsample of the assemblages found in wooded areas and parks.

\section{Species diversity and richness}

The shape of the rarefaction curve showing the expected cumulative number of ant species in relation to the number of samples is relatively flat and the $95 \%$ confidence intervals for the Mao Tau estimator and ACE overlap. However, the number of species recorded in only one sample (i.e. unique) was eight and is independent of the number of samples (Fig. 4).

The species diversity of the ant assemblages recorded in the different biotopes within the city differed. The ant 


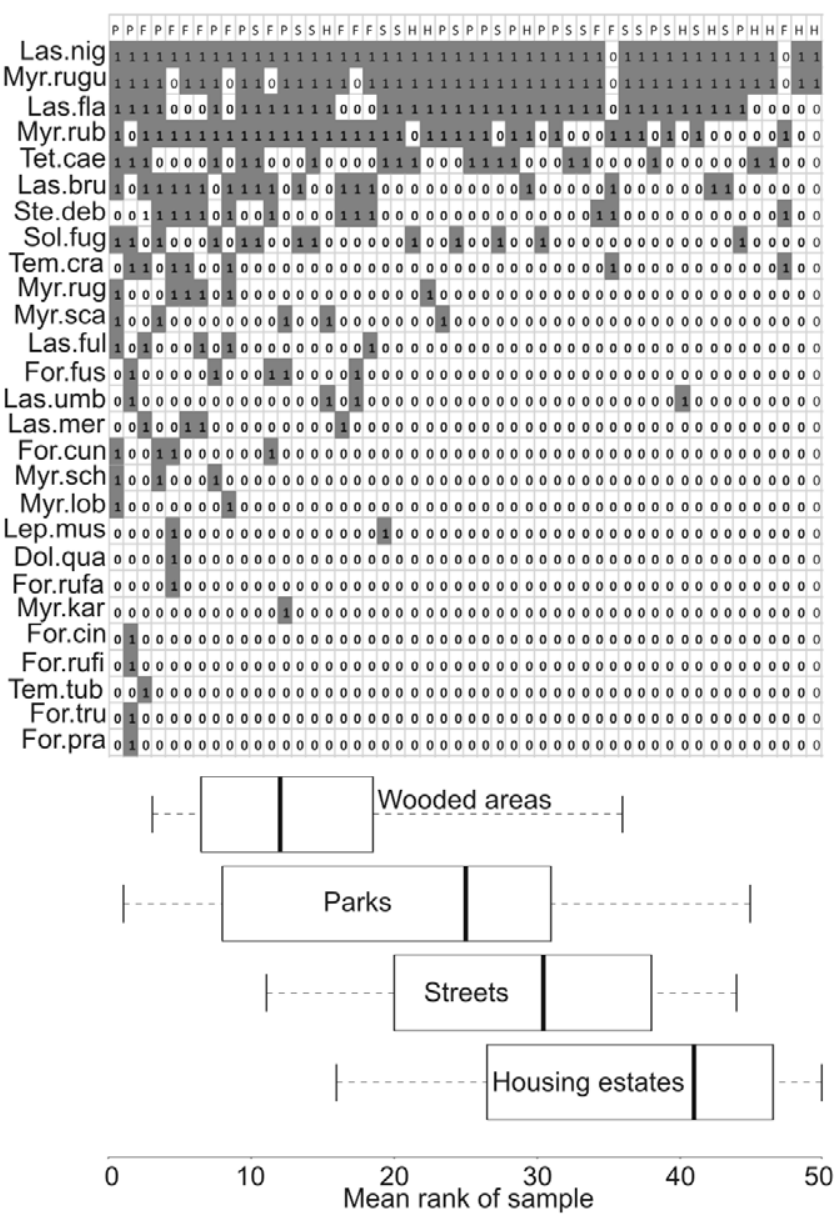

Fig. 3. The maximally packed "species * plots" matrix output of the nestedness analysis. If a species is present in a given cell it is marked " 1 " and is coloured grey. Boxplots of the variability in the means sample ranks for each of the four biotopes is presented below the matrix.

assemblages in the green areas bordering streets were the least, and the parks and wooded areas the most diverse. The expected cumulative number of species for 11 randomly selected samples ranged from 7.8 for street green areas to 19.6 for parks (Fig. 4). The mean values of the diversity index to some extent followed the results of the rarefaction analysis: they were $1.29,1.38,1.75$ and 2.53 for the biotopes in the housing estates, streets, parks and wooded areas, respectively, and the differences were significant (Kruskal-Wallis, $\chi^{2}=17.89, d f=3, P<0.001$ ).

\section{Species-specific response to urbanization}

The redundancy analysis showed a relationship between the distribution of ant species and biotopes. Several species, including Stenamma debile, Lasius brunneus, Temnothorax crassispinus and Lasius fuliginosus, were recorded mainly in wooded areas, whereas Lasius niger seemed to avoid this biotope. Myrmica rugulosa and Tetramorium caespitum were recorded predominantly in green areas bordering streets and occurred less often in parks (Fig. 5). In contrast, Lasius flavus, Formica cunicularia and Solenopsis fugax were recorded mainly in parks. In general, the variability in the activity density of
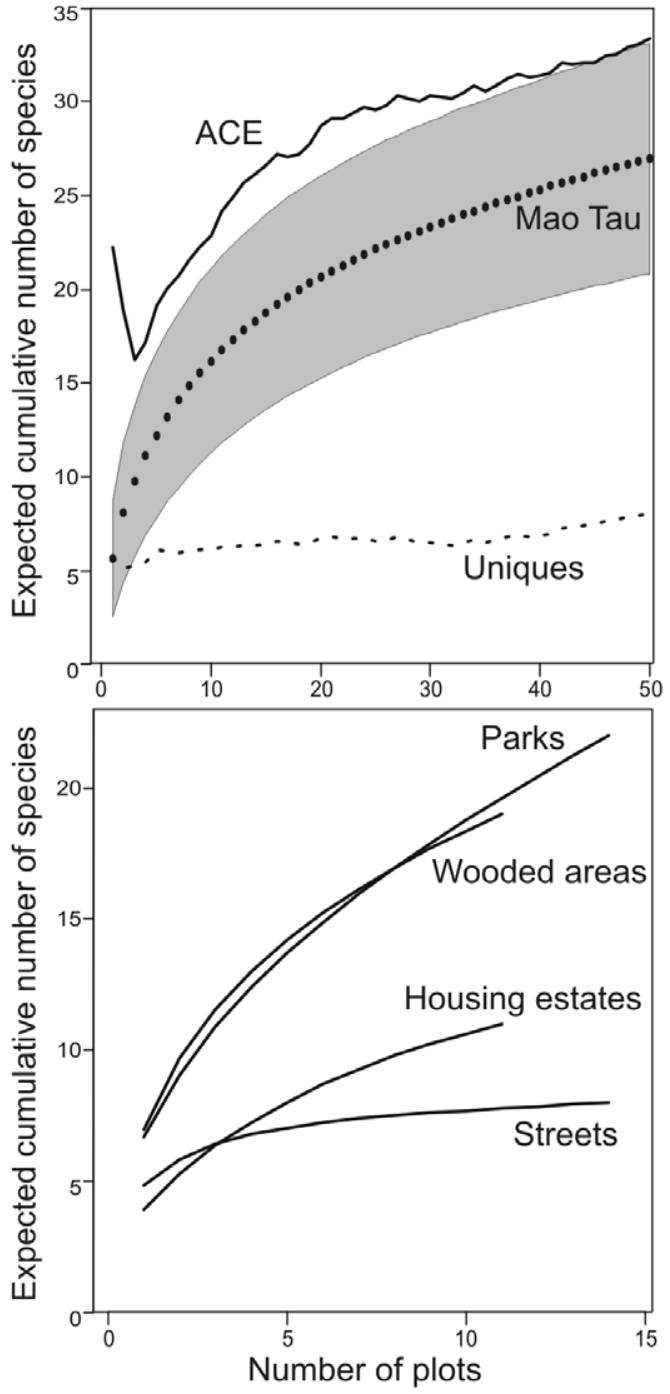

Fig. 4. Expected cumulative number of ant species as a function of the number of plots sampled. Upper subplot (pooled results): Mao Tau estimator (i.e. observed species richness) with upper and lower 95\% confidence intervals (grey area), abundance coverage indicator (ACE) (i.e. number of species corrected for those not recorded in the samples) and unique species (those that occurred in only one sample). In the lower subplot the Mao Tau estimators are presented for each biotope. Note that the $\mathrm{x}$ and $\mathrm{y}$ scales on the two subplots differ.

the ants significantly depended on the canonical axes (Monte Carlo test, trace $=0.216, F=3.103, P=0.0304$ ). The species richness of the samples was highest in wooded areas and increased with increasing distance from the city centre; a similar pattern was recorded for the Shannon diversity index values (Fig. 5).

\section{Species composition and ecological profile}

In the urban green areas of Warsaw the most abundant species were Lasius niger $(70.8 \%$ of the total ant activity density) and Myrmica rugulosa (19.6\%), a polytope (species occurring in many different habitats, e.g. forests of various types; see Czechowski et al., 2002) of open habitats and an oligotope (species occurring in similar habitats, e.g. in various coniferous forests; see Czechow- 


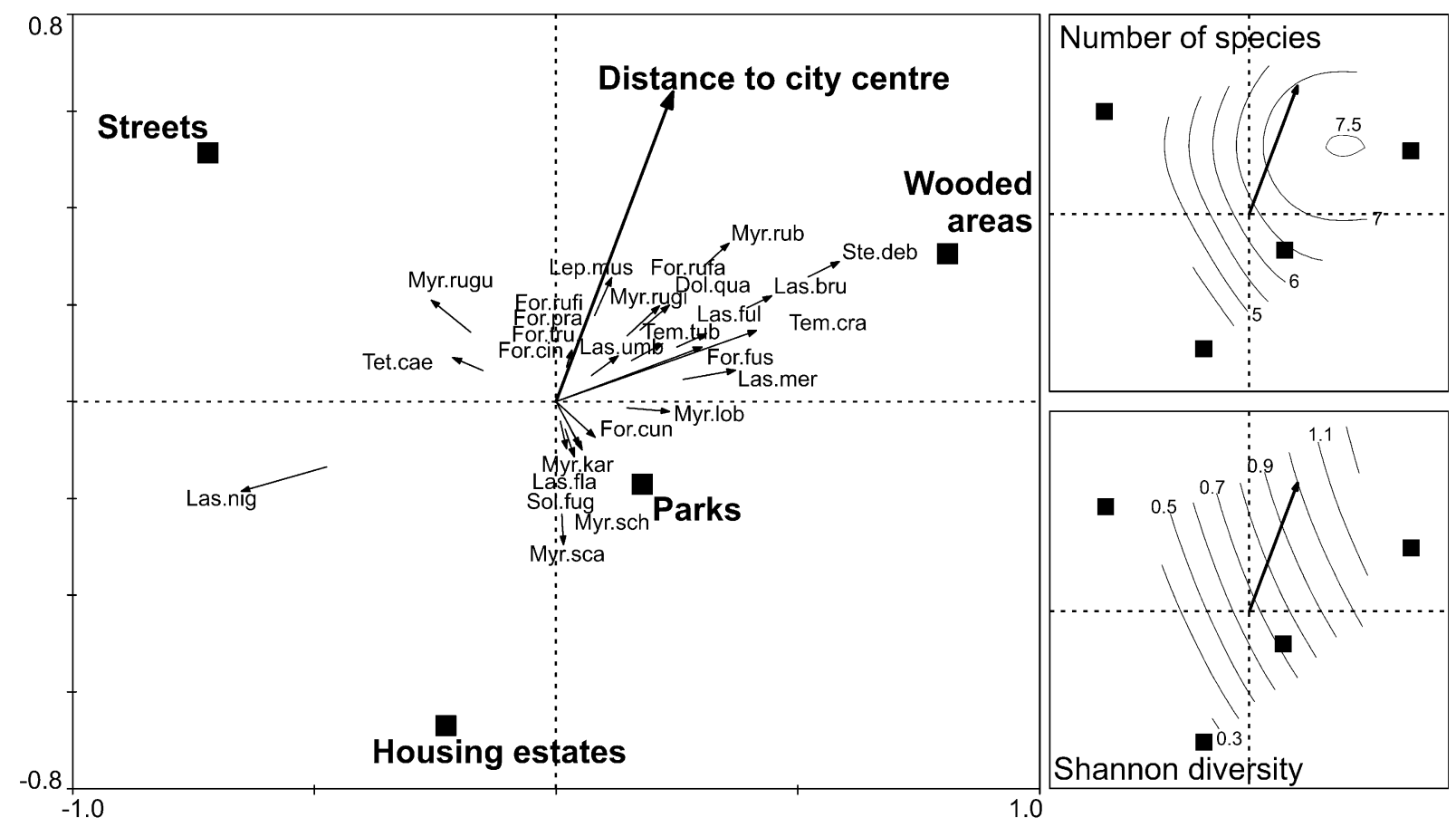

Fig. 5. Redundacy analysis (RDA) biplot showing vectors for the different ant species and explanatory variables along the first two axes. The two plots on the right show the variability in number of species and species diversity (presented as isolines fitted by general additive models) with explanatory variables.

ski et al., 2002) of dry grasslands, respectively. Myrmica rubra and Lasius flavus, both eurytopes (species which can live both in forest and open areas and manifest no distinct preference for any type of habitat or ecological factor; see Czechowski et al., 2002) and L. brunneus (an oligotope of deciduous forests) were lower in this ranking $(3.3 \%, 2.8 \%$ and $1.3 \%$, respectively). All the remaining species were less well represented (Fig. 2). The five most represented species also predominated in particular types of urban green areas.

Of the other species, Tetramorium caespitum and Stenamma debile, are worth mentioning in the context of their constancy in urban green areas. T. caespitum, a polytope of dry habitats, occurred in $57 \%$ of the park plots, $50 \%$ of the street plots $27 \%$ of the housing estate plots, and it was almost totally absent in wooded areas. In contrast, $S$. debile, an oligotope of deciduous forest, was recorded in all the urban wooded plots but almost never in lawn biotopes.

The activity density of urban ant assemblages differed greatly both within and between the biotopes studied. On average, it was highest in green areas bordering streets where the mean value was $227.1 \pm 30.1$ (range 108.6-879.6). In housing estate green areas, it was $145 \pm$ $24.9(10.0-245.6)$ and in parks 111.5 \pm 15.2 (38.1-429.1). The activity density of ants in wooded areas $[35.1 \pm 3.2(13.6-64.2)]$ was, on average, several times lower than in lawns. The differences in activity density between the biotopes were statistically significant (ANOVA, $F=5.46, d f=3 ; P=0.003$ ).

Due to the usually marked dominance of a single species, the ecological profiles of ant assemblages in particular urban biotopes were determined mainly by the nature of the dominant species. Therefore, the assemblages in urban lawn biotopes, irrespective of their location, are made up first of all of individuals of species with the greatest ecological amplitude, i.e. eurytopic Lasius flavus, polytopic L. niger and Tetramorium caespitum, and an oligotopic species of dry grasslands, Myrmica rugulosa. These four species are common in anthropogenic biotopes. All of them are more or less thermophilic and (except for the subterranean $L$. flavus) fairly xerophilic. Altogether, in the green areas of urban parks, housing estates and bordering streets, 93.5\%, 99.5\% and $99.4 \%$ of the ants, respectively, belonged to these species. The composition of the myrmecofauna of urban wooded areas was much more complex. Besides eurytopes (Myrmica rubra) and polytopes (L. niger, Myrmica ruginodis) (in total, 58.4\%), oligotopes of deciduous forests were fairly numerous, and included two dendrobionts, Lasius brunneus and L. fuliginosus (30.4\%). What is more, the two polytopes mentioned above, L. niger and M. ruginodis, differ radically in their habitat requirements: the first prefers open biotopes (including anthropogenic ones), the second is common in forests, but rare in open humanaltered biotopes. While all three species of the genus Lasius tend to be thermophilic and mesohygrophilic, the two species of Myrmica are oligothermophilic and hygrophilic.

\section{DISCUSSION}

That ant species in an urbanized landscape are not randomly distributed is the main finding of this study. We found that the pattern of ant assemblages in the four urban biotopes studied was significantly nested. The species composition recorded in green areas in housing 
estates and bordering streets constituted subsamples of the assemblages recorded in urban wooded areas and parks (Fig. 3). This result confirms the proposed hypothesis of an hierarchical ordering of the biotopes studied and emphasizes the great biological importance of urban parks (lawns with solitary, often old trees or clusters of trees, many species of herbaceus plants and shrubs) and wooded areas (remnants of original woodland cover) in determining the diversity of species present in a city. Some research emphasizes the positive role of a single tree, which becomes a refuge for many arthropod species, not only ants (Yasuda \& Koike, 2009). Authors also stress the importance of the size of trees, the bigger the tree the more species, in increasing species richness. Biodiversity in wooded areas is associated with the size of habitat patches (Mabelis, 2005). However we were unable to correlate species richness with patch size as this was not recorded when the samples were collected in 1974-1978 and it was not possible to measure it retrospectively. If we consider the effect of management on the four biotopes, it was significantly less in the wooded areas than in the three lawn biotopes. In addition, parks and wooded areas are the most pristine for city dwellers because of their recreational value (DeStefano \& DeGraaf, 2003). Parks are areas of natural forest greatly modified for recreational purposes. Wooded areas remain natural, to some extent, but like parks are subject to high levels of human activity, but nevertheless still contain much of the biodiversity of the city and may serve as refuges (Kadlec et al., 2008) for most ant species.

The results obtained are in accordance with those of other recent studies in reporting a nested pattern of assemblages of organisms along a gradient of urbanization and increase in urban pressure on different biotopes. For example, Pećarević et al. (2010) found strongly nested ant fauna in the street medians of New York City. Fernandez-Juricic (2000, 2002) found a significantly nested structure of bird assemblages in green areas in Madrid, Spain, which was associated with the size of a park area and its age. Also assemblages of other organisms living in cities were reported to follow a nested pattern (e.g. plants - Stiles \& Scheiner, 2008; Carabidae Weller \& Ganzhorn, 2004). Therefore, the spatial distribution of ant species in the green areas studied in Warsaw seems to confirm the hypothesis put forward by Kondoh (1978), that man-made habitats are the main determinant of species richness and, in turn, nestedness in a city landscape. Further analysis exposed one more important association that between species richness and distance from the city centre. Redundancy analysis (Fig. 5) indicates an increase in the Shannon diversity index and species richness with increasing distance from the city centre.

The sampling effort was sufficient to make reliable inferences about the spatio-temporal variability of ants inhabiting Warsaw. The 95\% confidence intervals of the total species richness estimator (ACE; Fig. 4) overlapped the Mao Tau estimator, which means that the great majority of the species present in the city were recorded. Twenty-seven species of ants were recorded in Warsaw green areas in the 1970s (Fig. 2). They constitute 29\% of the ant diversity occurring naturally in Poland and nearly $51 \%$ of all the species reported in the Mazovia Lowland (according to Czechowski et al., 2002; updated). It is worth stressing that despite urbanization ant species richness in Warsaw is relatively high as in several hectares of city parks and wooded areas we recorded over half of the species richness of the region, which covers ca. 40,000 $\mathrm{km}^{2}$. This indicates the importance of urbanized landscapes for maintaining biodiversity. The relative species richness of the urban ant fauna in Warsaw is similar to that recorded in some other European cities. In Sofia, the percentage of species found in the city of the total number recorded for Bulgaria is 30\% (Antonova \& Penev, 2006), in Vienna, relative to the whole of Austria, it is also 30\% (Schlick-Steiner \& Steiner, 1999). In another Austrian city, Linz and two German cities, Mainz and Cologne, however the recorded percentages are $21 \%, 21 \%$ and 20\%, respectively (Lippke \& Cölln, 1991; Dauber \& Eisenbeis, 1997; Ambach, 1999).

In Warsaw, the most polluted, dry and floristically poor street lawns were the least diverse in myrmecofauna, with as few as eight species of ants. Studies carried out in Belgium also reveal that the green area bordering streets are the poorest of all the urban habitats examined (Gaspar \& Thirion, 1978) and in the street medians (lawns) along boulevards in New York City, there are a similar number (13) of ant species (Pećarević et al., 2010). The situation recorded in housing estates was similar, with only 11 species of ants recorded. It should be stressed that green areas bordering streets and in housing estates comprise an overwhelming majority of the total urban green area, and consequently, their myrmecofauna is the most characteristic for the city. In these two dominating biotopes in Warsaw, there were only 12 species of ants and two of them, Lasius niger and Myrmica rugulosa, made up more than $90 \%$ of the entire activity density of ants. Such low species richness and diversity, combined with a high predominance of a single species is most probably due to the strongly selective effect of specific urban habitat factor(s), which favour species well adapted to impoverished habitats (Pisarski, 1990; Vepsäläinen, 2008). This is clearly the case of Lasius neglectus, a recently described species (van Loon et al., 1990). In the 1990s, it was found in Warsaw (Czechowska \& Czechowski, 1999, 2003). In Europe, this polygynous species occurs nearly exclusively in cities, where it can occupy large areas of several hectares and displace other ant species (Cremer et al., 2006). In wooded areas and parks 21 species were recorded, with parks strongly dominated by a few species (Lasius niger, Myrmica rugulosa, Myrmica rubra, Lasius flavus) and the ant assemblages in woodlands much more diverse, and the percentages of abundances of species much more evenly distributed, which accords with the general rule that impoverished assemblages have a few dominant species (Krebs, 1994). This finding emphasizes the high ecological importance of these two types of urban green areas. In addition, the shapes of the rarefaction curves (Fig. 4) indicate the presence of some unrevealed species 
in parks and wooded areas whereas the relatively flat estimator in the case of street green areas and those in housing estates indicate it is unlikely that other species occur there. Redundancy and rarefaction analyses emphasise the importance of biotopes that have undergone relatively little transformation (less polluted and degraded).

As shown by many other myrmecological studies conducted in cities (e.g. Yamaguchi, 2004; Antonova, 2005; Vepsäläinen et al., 2008), Lasius niger is numerically dominant in the urban green areas of Warsaw. The percentage made up of the second most abundant species, Myrmica rugulosa, was much lower (ca. 20\%). Only in wooded areas, the least urban of the four biotopes studied, did Myrmica rubra and Lasius brunneus outnumber these two species. The redundancy analysis clearly showed a strong association of $L$. niger and $M$. rugulosa with Warsaw street-side and housing estate green areas (Fig. 5). They seem to be well adapted to the extreme urban conditions of Central Europe, as both are common xero- and thermophilic dwellers of grasslands and are common in anthropogenic habitats. In addition, they can tolerate high levels of pollution (Pisarski \& Czechowski, 1978). According to Kondoh's (1978) L. niger, Tetramorium jacoti Wheel. and Formica japonica Motsch. are likely to be the only species of ants surviving in the worst conditions in urban areas in Japan.

It should be stressed that the quantitative relations revealed within ant assemblages strongly depend on the sampling method. Data from pitfall traps reflect the outcome of the activity of epigean ants rather than the size of their populations (see e.g. Pećarević et al., 2010). Based on soil samples, the species dominating the ant assemblages in lawns in Warsaw was the subterranean Lasius flavus. It made up $70 \%$ of the total population of ants whereas $L$. niger, in second place, made up $23 \%$. In third place $(6 \%)$ was Solenopsis fugax (Latr.) and the percentage abundance of Myrmica rugulosa was quite low (0.5\%) (Pisarski \& Czechowski, 1978). On the other hand, pitfall trapping is the most common method used in towns and the most suitable for comparative studies. The densities of L. flavus can be underestimated even in studies based on nest counts. In the intensely cultivated Warsaw lawns, L. flavus produced completely invisible, totally underground (moundless) nests (Pisarski \& Czechowski, 1978). Based on soil samples the most important (abundant and/or most constant) ant species in Warsaw green areas (lawns and/or wooded areas), are in alphabetical order: Lasius brunneus, L. flavus, L. niger, Myrmica rubra, M. rugulosa, Solenopsis fugax, Stenamma debile and Tetramorium caespitum. All these species also occur in different biotopes in Sophia (see Antonova, 2005) and a few of these species are the dominant species in Helsinki (Lasius niger, Myrmica rubra, $L$. flavus; see Vepsäläinen et al., 2008).Within the group of dominant species in Warsaw, both xerophilic (at least mesoxerophilic) and thermophilic (at least mesothermophilic) forms prevailed: Lasius brunneus, L. niger, $M$. rugulosa, $S$. fugax, $S$. debile and $T$. caespitum. In terms of the range of ecological plasticity, half of these were eury- topes and polytopes: L. flavus, L. niger, M. rubra and $T$. caespitum; and the rest oligotopes and no stenotopes (species closely associated with one habitat, e.g. mires or xerothermal grasslands; see Czechowski et al., 2002). Moreover, most of the species listed are synanthropes (see e.g. Seifert, 2007). The absence of Lasius platythorax Seifert from wooded areas in Warsaw is characteristic (see Czechowski \& Ślipiński, 2008) as this species generally avoids anthropogenic habitats (Czechowski et al., 2002; Seifert, 2007) despite the presence there of suitable nesting sites.

The ecological features of an urban myrmecofauna presented in this study are typical not only for ants, but also many other urban invertebrate assemblages in Warsaw (see Czechowski \& Pisarski, 1981) and most probably all other temperate zone cities, and are associated with specific urban conditions. For example, the high prevalence of xero- and thermophilic species is associated with the lower humidity and higher mean temperature in urban habitats than in non-urban areas. A reverse tendency is observed in the Mediterranean region, where urban areas are regularly watered artificially. Because of this, the percentages of relatively hygrophilic species of ant in, for example, North African towns are significantly higher than in natural habitats in that climate (Bernard, 1974).

The structure of the ant assemblages in the four urban biotopes studied differed significantly. Since ants are thought to be reliable indicators of ecosystem quality and species richness (e.g. Yamaguchi, 2004; Penev et al., 2008; Pećarević et al., 2010) this result may be relevant to developing a general strategy for conserving biodiversity in an urban environment. Ants are ubiquitous organisms (Hölldobler \& Wilson, 1990) living in most natural habitats and with crucial functions (Underwood \& Fisher, 2006) as ecosystem engineers (Folgarait, 1998) involved in nutrient cycling (Levieux, 1983; Lal, 1988), soil turnover (Lobry de Bruyn \& Conacher, 1994), aeration (Sanford et al., 2009), seed dispersal and plant protection (Christian, 2001). However, our study shows that green areas bordering streets, the most common type of greenery in Warsaw (70\% of total urban green area), are so severely degraded or managed that only a few species can survive there. Lasius niger and Myrmica rugulosa are dominant there and as more recent research (Czechowska \& Czechowski, 2003) shows Lasius neglectus can also locally dominate in these areas.

ACKNOWLEDGEMENTS. We are grateful to an anonymous referee for reviewing the manuscript, numerous pertinent corrections and useful comments on a previous version. B. Przybylska and then the language Editor kindly improved the English and M. Gąsior helped with preparing Fig. 1. Most importantly, this paper would not exist if the late Professor B. Pisarski had not identified in the 1980s the large number of ants in the samples collected for this study.

\section{REFERENCES}

Agosti D., Majer J.D., Alonso L.E. \& Schultz T.R. 2000: Ants: Standard Methods for Measuring and Monitoring Biodiversity. Smithsonian Institution Press, Washington, $20+$ $280 \mathrm{pp}$. 
Амвасн J. 1999: Verbreitung der Ameisenarten (Hymenoptera: Formicidae) im Linzer Stadtgebiet (Oberösterreich) und ihre Bewertung aus stadtökologischer Sicht. Naturk. Jb. Stadt Linz 44: 191-320.

Angilletta M.J., Wilson R.S., Niehaus A.C., Sears M.W., Navas C.A. \& Ribeiro P.L. 2007: Urban physiology: city ants possess high heat tolerance. PLOS ONE 2:e258

Andersen A.N., Hoffmann B.D., Müller J.W. \& Griffiths A.D. 2002: Using ants as bioindicators in land management: simplifying assessment of ant community responses. J. Appl. Ecol. 39: 8-17.

Antonova V. 2005: Species diversity and distribution of ants in different habitats in the parks of the city of Sofia. In Chipev N. \& Bogoev V. (eds): Biodiversity, Ecosystems, Global changes. I-st National Scientific Conference in Ecology. Petekston Press, Sofia, pp. 231-236.

Antonova V. \& Penev L. 2006: Change in the zoogeographical structure of ants (Hymenoptera, Formicidae) caused by urban pressure in the Sofia region (Bulgaria). Myrmec. Nachr. 8: 271-276.

Atmar W. \& Patterson B.D. 1993: The measure of order and disorder in the distribution of species in fragmented habitat. Oecologia 96: 373-382.

Beever E.A., Tausch R.J. \& Brussard P.F. 2003: Characterizing grazing disturbance in semiarid ecosystems across broad scales, using diverse indices. Ecol. Appl. 13: 119-136.

Bernard F. 1974: Les fourmis des rues de Kenitra (Maroc) (Hym.) Biologie, densité, comparaison avec d'autres régions nord-africaines. Bull. Soc. Entomol. Fr. 79: 178-183.

BotKIn D.B. \& Beveridge C.E. 1997: Cities as environments. Urban Ecosyst. 1: 3-19.

Colwell R.K. 2005: EstimateS: Statistical Estimation of Species Richness and Shared Species from Samples. Version 7.5. http://purl.oclc.org/estimates. Assessed 20 December 2010.

Chao A., Li P.C., Agatha S. \& Foissner W. 2006: A statistical approach to estimate soil ciliate diversity and distribution based on data from five continents. Oikos 114: 479-493.

Christian C.E. 2001: Consequences of a biological invasion reveal the importance of mutualism for plant communities. Nature 413: 635-639.

Clarke K.M., Fisher B.L. \& LeBuhn G. 2008: The influence of urban park characteristics on ant (Hymenoptera, Formicidae) communities. Urban Ecosyst. 11: 317-334.

Cremer S., Ugelvig L.V., Lommen S.T.E., Petersen K.S. \& PedERSEN J.S. 2006: Attack of the invasive garden ant: aggression behaviour of Lasius neglectus (Hymenoptera: Formicidae) against native Lasius species in Spain. Myrmec. Nachr. 9: 13-19.

Czechowska W. \& Czechowski W. 1999: Lasius neglectus Van Loon, Boomsma et Andrasfalvy, 1990 (Hymenoptera, Formicidae), nowy dla Polski gatunek mrówki, w Warszawie. [Lasius neglectus Van Loon, Boomsma et Andrasfalvy, 1990 (Hymenoptera, Formicidae), a new ant species for Poland, in Warsaw.] Przegl. Zool. 43: 189-191 [in Polish].

Czechowska W. \& Czechowski W. 2003: Further record of Lasius neglectus Van Loon, Boomsma et Andrasfalvy (Hymenoptera: Formicidae) for Warsaw, with a key to the Polish species of the subgenus Lasius s. str. Fragm. Faun. 46: 195-202.

Czechowski W. 1991: Comparison of the myrmecofaunas (Hymenoptera, Formicoidea) of tree stands and lawns in Warsaw parks. Fragm. Faun. 35: 179-184.

Czechowski W. \& Pisarski B. 1981: Species composition and origin of the fauna of Warsaw. Part 1. Memorab. Zool. 34: $1-259$.
Czechowski W. \& Pisarski B. 1990: Ants (Hymenoptera, Formicoidea) of the Vistula escarpment in Warsaw. Fragm. Faun. 33: 109-128.

CZechowsKi W. \& ŚLIPIŃSKi P. 2008: No Lasius platythorax Seifert (Hymenoptera: Formicidae) in the urban greenery of Warsaw? Pol. J. Ecol. 56: 541-544.

Czechowski W., Czechowska W. \& Palmowska A. 1990: Arboreal myrmecofauna of Warsaw parks. Fragm. Faun. 34: $37-45$.

Czechowski W., Radchenko A. \& Czechowska W. 2002: The Ants of Poland. Museum and Institute of Zoology PAS, Warsaw, $200 \mathrm{pp}$.

DAUBer J. \& EISENBeis G. 1997: Untersuchungen zur Ameisenfauna einer urbanen Landschaft am Beispiel der Stadt Mainz. Abh. Ber. Naturkmus. Görlitz 69: 237-244.

DeStefano S. \& DeGraaf R.M. 2003: Exploring the ecology of suburban wildlife. Front. Ecol. Environ. 1: 95-101.

Fernandez-Juricic E. 2000: Bird community composition patterns in urban parks of Madrid: The role of age, size and isolation. Ecol. Res. 15: 373-383.

FernandeZ-JuRICIC E. 2002: Can human disturbance promote nestedness? A case study with breeding birds in urban habitat fragments. Oecologia 131: 269-278.

Folgarait P.J. 1998: Ant biodiversity and its relationship to ecosystem functioning: a review. Biodiv. Conserv. 7: $1221-1244$.

Gaspar C.H. \& Thirion C. 1978: Modification des populations d'hyménoptères sociaux dans des milieux anthropogènes. Memorab. Zool. 29: 61-77.

Gotelli N.J. \& Colwell R.K. 2001: Quantifying biodiversity: procedures and pitfalls in the measurement and comparison of species richness. Ecol. Lett. 4: 379-391.

HölLDOBLER B. \& Wilson E.O. 1990: The Ants. Harvard University Press, Cambridge, 732 pp.

JIM C.Y. 1998: Soil characteristics and management in an urban park in Hong Kong. Environ. Manag. 22: 683-695.

Kadlec T., Benes J., Jarosik V. \& Konvicka M. 2008: Revisiting urban refuges: Changes of butterfly and burnet fauna in Prague reserves over three decades. Landsc. Urban Planning 85: $1-11$.

KASPARI M. \& MAJER J.D. 2000: Using ants to monitor environmental change. In Agosti D., Majer J., Alonso E. \& Schultz T.R. (eds): Ants: Standard Methods for Measuring and Monitoring Biodiversity. Smithsonian Institution Press, Washington, pp. 89-98.

KonDOH M. 1978: A comparison among ant communities in the antropogenic environment. Memorab. Zool. 29: 79-92.

Kubicka A., Chudzicka E. \& Wysocki C. 1986: Structure of the fauna of Warsaw. The study area. Memorab. Zool. 41: 11-69.

Krebs C.J. 1994: Ecology. The Experimental Analysis of Distribution and Abundance. Harper Collins, New York, 801 pp.

LAL R. 1988: Effects of macrofauna on soil properties in tropical ecosystems. Agric. Ecosyst. Environ. 24: 101-116.

Lapeva-Gjonova A. \& Atanasova M. 2004: A faunistic investigation of the ants (Hymenoptera, Formicidae) in the city of Sofia. In Penev L., Niemalä J., Kotze D.J. \& Chipev N. (eds): Ecology of the Cityof Sofia. Species and Communities in Urban Environment. Pensoft, Sofia-Moscow, pp. 417-422.

LEPŠ J. \& ŠMILAUER P. 2003: Multivariate Analysis of Ecological Data using CANOCO. Cambridge University Press, Cambridge, $280 \mathrm{pp}$.

LevieuX J. 1983: The soil fauna of tropical savannas. IV. The ants. In Bourlière F. (ed.): Tropical Savannas. Elsevier, Amsterdam, pp. 525-540.

Levins R. 1968: Evolution in Changing Environments. Princeton University Press, Princeton, 120 pp. 
LIPPKE S. \& CöLlN K. 1991: Über die Ameisen (Formicidae) von Köln. Verh. Westdt. Entomologentag 1990: 87-90.

Lobry De Bruyn L.A. \& CONACHER A.J. 1994: The bioturbation activity of ants in agricultural and naturally vegetated habitats in semi-arid environments. Austral. J. Soil Res. 32: 555-570.

Mabelis A.A. 2005: Green infrastructure of a city and its biodiversity: take Warsaw as an example. Fragm. Faun. 48: 231-247.

MatuszKIewicz W. 1981: Przewodnik do oznaczania zbiorowisk ro slinnych Polski. [A Guide to Identification of the Plant Associations of Poland.] Państwowe Wydawnictwo Naukowe, Warszawa, $298 \mathrm{pp}$.

Pećarević M., Danoff-Burg J. \& Dunn R.R. 2010: Biodiversity on Broadway - Enigmatic diversity of the societies of ants (Formicidae) on the streets of New York City. PLoS ONE 5(10): e13222. doi:10.1371/journal.pone.0013222

Penev L., Stoyanov I., Dedov I. \& Antonova V. 2008: Patterns of urbanization in the city of Sofia as shown by carabid beetles, ants and molluscs. In Penev L.T. \& Erwin Assmann T. (eds): Back to the Roots and Back to the Future. Towards a New Synthesis amongst Taxonomic, Ecological and Biogeographical Approaches in Carabidology. Proceedings of the XIII European Carabidologists Meeting, Blagoevgrad, August 20-24, 2007. Pensoft Series Faunistica 75: 483-509.

Philpott S.M., Perfecto I., Armbrecht I. \& Parr C.L. 2010 Ant diversity and function in disturbed and changing habitats. In Lach L., Parr C.L. \& Abbott K.L. (eds): Ant Ecology. Oxford University Press, New York, pp. 137-157.

Pisarski B. \& CZechowski W. 1978: Influence de la pression urbaine sur la myrmécofaune. Memorab. Zool. 29: 109-128.

PISARSKi B. 1982: Ants (Hymenoptera, Formicoidea) of Warsaw and Mazovia. Memorab. Zool. 36: 73-90.

PISARSKI B. 1990: The invertebrate fauna of urbanized areas of Warsaw. In Luniak M. (eds): Urban Ecological Studies in Central and Eastern Europe. Ossolineum, Wrocław, pp. 98-111.

PISARSKI B. \&VEPSÄLÄINEN K. 1987: Geographic variability of myrmecofauna of urban areas. In Eder J. \& Rembold H. (eds): Chemistry and Biology of Social Insects. J. Peperny, München, pp. 604.

Rosenberg V.A., Bocharnikov V.N. \& Krasnopeev S.M. 2000: Biological diversity in the Sikhote-Alin forests and measures of its conservation. In Hansen M. \& Burk T. (eds): Integrated
Tools for Natural Resources Inventories in the 21st Century. Gen. Tech. Rep. NC-212. U.S. Dept. of Agriculture, Forest Service, North Central Forest Experiment Station, St. Paul, MN, pp. 326-333.

Sanford M.P., Manley P.N. \& MurPhy D.D. 2009: Effects of urban development on ant communities: Implications for ecosystem services and management. Conserv. Biol. 23: 131-141.

SeIfERT B. 2007: Die Ameisen Mittel- und Nordeuropas. Lutra Verlags und Vertriebsgesellschaft, Tauer, $368 \mathrm{pp}$.

SChlick-Steiner B.C. \& Steiner F.M. 1999: Faunistischökologische Untersuchungen an den freilebenden Ameisen (Hymenoptera: Formicidae) Wiens. Myrmec. Nachr. 3: 9-53.

Stiles A. \& Scheiner S.M. 2008: Nestedness of remnant Sonoran desert plant communities in metropolitan Phoenix, Arizona. Ecology 89: 2473-2481.

UlRICH W. 2006: Nestedness - a FORTAN Program for Calculating Ecological Matrix Temperatures. www.uni.torun.pl/ $\sim$ ulrichw

Ulrich W., Almeida-Neto M. \& Gotelli N.C. 2009: A comsumer's guide to nestedness analysis. Oikos 118: 3-17.

Underwood E.C. \& Fisher B.L. 2006: The role of ants in conservation monitoring: If, when, and how. Biol. Conserv. 132: 166-182.

VEPSÄLÄINEN K. \& PISARSKi B. 1982: The structure of urban ant communities along the geographical gradient from north Finland to Poland. In Luniak M. \& Pisarski B. (eds): Animals in Urban Environment. Polish Academy of. Sciences, Wrocław, pp. 103-113.

VEPSÄLÄINEN K., IKonen H. \& KoIvUla M.J. 2008: The structure of ant assemblages in an urban area of Helsinki, southern Finland. Ann. Zool. Fenn. 45: 109-127.

Weller B. \& GANZHoRn J.U. 2004: Carabid beetle community composition, body size, and fluctuating asymmetry along an urban-rural gradient. Basic Appl. Ecol. 5: 193-201.

YAMAGUCHI T. 2004: Influence of urbanization on ant distribution in parks of Tokyo and Chiba City, Japan. I. Analysis of ant species richness. Ecol. Res. 19: 209-216.

YASUda M. \& KoIKe F. 2009: The contribution of the bark of isolated trees as habitat for ants in an urban landscape. Landsc. Urban Planning 92: 276-281.

Received August 19, 2011; revised and accepted November 18, 2011 